\title{
Commentary What is a virulence factor?
} Alan S Cross

Center for Vaccine Development, University of Maryland School of Medicine, 685 W. Baltimore Street, HSF 1 480, Baltimore, MD 21201, USA

Corresponding author: Alan S Cross, across@medicine.umaryland.edu

Published: 2 December 2008

Critical Care 2008, 12:196 (doi:10.1186/cc7127)

This article is online at http://ccforum.com/content/12/6/196

(c) 2008 BioMed Central Ltd

See related review by Webb and Kahler, http://ccforum.com/content/12/6/234

\begin{abstract}
Bacterial virulence factors enable a host to replicate and disseminate within a host in part by subverting or eluding host defenses. The use of genomic techniques has led to the identification of new virulence factors that may serve as targets for new therapies. These putative virulence factors must be rigorously evaluated with in vitro and in vivo studies with an awareness of the technical limitations of each approach as well as an assessment of the prevalence of this factor in clinical bacterial isolates retrieved from appropriately controlled epidemiologic studies.
\end{abstract}

Infections are a leading cause of death in the intensive care unit. With the rising incidence of bacteria resistant to multiple antibiotics and a decreasing antibiotic drug pipeline, clinicians have sought additional therapies to supplement the current standard of care. Originally, such therapies, including anti-endotoxin antibodies and intravenous immunoglobulin, targeted the causative organisms. However, these efforts were supplanted by efforts to modulate the host responses to these organisms that were considered to be responsible for sepsis. Despite extensive clinical trials with biologic response modifiers, there is only one intervention licensed by the US Food and Drug Administration, drotrecogin alpha (Xigris ${ }^{\circledR}$ ). Consequently, attention has now returned toward targeting the organisms. This development has been greatly assisted by the advent of genomics and systems biology, which have led to the identification of previously unrecognized targets on bacteria. These disciplines, in conjunction with advances in molecular biologic techniques, have led to striking advances in our understanding of the molecular pathogenesis of infection and the role of an ever-widening array of potential bacterial virulence factors. In their comprehensive review in this issue of Critical Care, Webb and Kahler [1] speculate that targeting virulence may be an attractive therapeutic strategy. Leaving aside the issues of drug formulation and/or delivery, what is required for the identification of a 'drugable' virulence target?
Pathogens are perhaps the pre-eminent cell biologists, having over the span of millennia identified special niches or strategies, not only to subvert host defenses, but in some instances (like the polysialic acid K1 capsule of Escherichia coli) to elude detection through bacterial mimicry (by which the bacterial 'wolf' wraps itself in the 'sheep's clothing' of the host's cell). As these authors point out, many of the virulence mechanisms are now defined at precise molecular and genetic levels. However, the likelihood of developing therapies that target such virulence factors will depend on subsequent rigorous experimentation. With in vitro studies, one can precisely delineate the mechanism of a putative virulence factor in a cellular phenotype of interest, but these studies are unable to assess the effect of a virulence determinant on more complex intercellular interactions. These studies often employ non-physiologic levels of the molecule of interest, accompanied by non-physiologic exposure times. Such long exposure times make it difficult to separate the early, primary effects of the virulence factor from those later effects (for example, at 24 hours) caused by secondary biologic cascades and/or the accumulation of mediators.

Consequently, it is necessary to complement in vitro with in vivo studies, but these, too, are fraught with technical pitfalls. To the authors' definition of virulence (ability to enter, replicate, and persist in a host), a virulence factor must enable the organism to do so with a relatively small inoculum. Simply giving high bacterial inocula that overcome host defenses does not allow one to make any determination of the importance of a virulence factor [2]. The route of bacterial administration is also critical [3]. Although it may be counterintuitive, administration of bacteria by the intravenous route results in a far greater $L D_{50}$ (median lethal dose) than when that same organism is administered either intraperitoneally or subcutaneously. Potent host defenses and clearance mechanisms are arrayed along the vasculature that clear the

LPS $=$ lipopolysaccharide. 
bloodstream of not only live bacteria but also inert particles. In the case of either intraperitoneal or subcutaneous challenge, there follows a 'race' between the ability of a pathogen to replicate at that site and the recruitment of host defenses.

Virtually every clinical bacteremic isolate, both Gram-positive and -negative, is serum-resistant [4]. As the authors acknowledge, lipopolysaccharide (LPS) and capsular phenotypes are the pre-eminent virulence determinants of Gram-negative bacteria. With the possible exception of bacteria on mucosal surfaces, strains of $E$. coli that lack a 'bacteremic phenotype' are highly avirulent [4]. For example, when $10^{10}$ colonyforming units of an enteropathogenic strain of $E$. coli, such as 0111, which is rarely found in the blood, were given intravenously to baboons, the organism was cleared quickly with little dissemination [5]. This observation has practical significance in evaluating putative virulence factors: the addition of a recognized virulence determinant, K1 capsule, into a deep rough LPS background did not confer any virulence to the organism [6]. This observation illustrates that, with the exception of some bacterial exotoxins, such as tetanus, diphtheria, and botulinus toxins, it is unusual for a single bacterial virulence factor by itself to initiate disease.

Finally, the importance of the $\mathrm{O}$ antigen and capsular polysaccharides as virulence determinants can be demonstrated by the fact that antibodies directed against the $O$ antigens of Gram-negative bacteria are highly protective $[7,8]$ and that many of the licensed vaccines against bacterial pathogens are directed against the capsular polysaccharides. These antigens are constitutively expressed, accessible, and rarely subject to change. Of the more than $150 \mathrm{O}$ serogroups of $E$. coli, 10 to 12 serogroups account for most cases of invasive infection, and of the more than 100 capsular polysaccharides, $\mathrm{K} 1$ is found in $20 \%$ of cases in adults [8]. This observation demonstrates another necessity in defining a 'drugable' virulence factor. Following both in vitro and in vivo studies, one must assess whether that virulence determinant can be found in bacteria retrieved from an appropriate clinical population. There is one caveat: if a virulence factor mimics a critical host molecule, therapeutic targeting of such a molecule risks harming the host. For example, the polysialic acid capsule of group $B$ meningococci mimics molecules present on the surface of developing human brain cells [9]. This consideration has had a profound impact on the development of meningococcal vaccines.

It is both timely and appropriate that Webb and Kahler re-focus attention on targeting the bacteria. Although we now have potent molecular tools for identifying novel virulence determinants, they must be evaluated by complementary in vitro and in vivo studies and supported by relevant clinical observations and an awareness of the pitfalls of each approach.

\section{Competing interests}

The author declares that he has no competing interests.

\section{References}

1. Webb SAR, Kahler CM: Bench-to-bedside review: Bacterial virulence and subversion of host defences. Crit Care 2008, 12:234.

2. Cross AS, Opal SM, Sadoff JC, Gemski P: Choice of bacteria in animal models of sepsis. Infect Immun 1993, 61:2741-2747.

3. Wolberg G, DeWitt CW: Mouse virulence of $\mathrm{K}(\mathrm{L})$ antigen-containing strains of Escherichia coli. J Bacteriol 1969, 100:730737.

4. Cross A, Asher L, Seguin M, Yuan L, Kelly N, Hammack C, Sadoff J, Gemski P Jr.: The importance of a lipopolysaccharide-initiated, cytokine-mediated host defense mechanism in mice against extraintestinally invasive Escherichia coli. J Clin Invest 1995, 96:676-686.

5. Wessels BC, Wells MT, Gaffin SL, Brock-Utne JG, Gathiram P, Hinshaw LB: Plasma endotoxin concentrations in healthy primates and during E. coli-induced shock. Crit Care Med 1988, 16:601-605.

6. Silver RP, Finn CW, Vann WF, Aaronson W, Schneerson R, Kretschmer PJ, Garon CF: Molecular cloning of the K1 capsular polysaccharide genes of $E$. coli. Nature 1981, 289:696-698.

7. Cross AS, Opal SM: Therapeutic intervention in sepsis with antibody to endotoxin: is there a future? J Endotoxin Res 1994, 1:57-69.

8. Cross AS, Gemski P, Sadoff JC, Orskov F, Orskov I: The importance of the $\mathrm{K} 1$ capsule in invasive infections caused by $E$. coli. J Inf Dis 1984, 149:184-193.

9. Kasper DL, Winkelhake JL, Zollinger WD, Brandt BL, Artenstein MS: Immunochemical similarity between polysaccharide antigens of Escherichia coli 07: K1(L):NM and group B Neisseria meningitides. J Immunol 1973, 110:262-268. 